\title{
Idiopathic Intracranial hypertension: A case report and a brief review of literature
}

\author{
Dr.Mahendra Wawhal ${ }^{1}$, Dr.Vajed Mogal ${ }^{2}$ Dr.Pratik Patil ${ }^{3}$, Dr.Rohit Kakde ${ }^{4}$, \\ Dr.Mahendra Sonawane ${ }^{5,}$ Dr. Pratap Gole ${ }^{6}$ \\ ${ }^{1}$ Senior Consulltant and Associate Professor ,MD ( General medicine) in the Department of Medicine, \\ Mahatma Gandhi Mission's Medical College and Hospital, CIDCO, N-6,Aurangabad, Maharashtra, India - \\ 431003 \\ ${ }^{2}$ Chief Resident in the Department of Medicine, Mahatma Gandhi Mission's Medical College and Hospital, \\ CIDCO, N-6,Aurangabad, Maharashtra, India - 431003 \\ ${ }^{3}$ Junior Resident in the Department of Medicine, Mahatma Gandhi Mission's Medical College and Hospital, \\ CIDCO, N-6,Aurangabad, Maharashtra, India - 431003 \\ ${ }^{4}$ Chief Resident in the Department of Medicine, Mahatma Gandhi Mission's Medical College and Hospital, \\ CIDCO, N-6,Aurangabad, Maharashtra, India - 431003 \\ ${ }^{5}$ Consultant Internist, MD ( General Medicine ) Tuljai hospital, Latur, maharashtra, India \\ ${ }^{6}$ Consultant internist and Gastroenterologist, Meenakshi hospital, Satara, Maharashtra, India
}

\begin{abstract}
We report a case of Idiopathic intracranial hypertension and Obesity .An obese female presented with headache and diplopia, since 2 weeks. She recovered very well with diamox and short steroid therapy. IIH is often idiopathic, proposed to be due to impaired cerebrospinal fluid absorbtion from the sub-arachnoid space across the arachnoid villi into the dural sinus. IIH is common in obese females and can lead to visual impairment but prompt diagnosis and treatment in most of the cases will prevent potentially permanent visual loss.
\end{abstract}

Key Words: Idiopathic intracranial hypertension, Obesity.

\section{Introduction}

Idiopathic intracranial hypertension ( $\mathrm{IIH}$ ) is a headache syndrome characterized by raised cerebrospinal fluid pressure in the absence of any cranial mass lesion or ventricular dilatation, normal spinal fluid composition, usually normal findings on neurological examination except for papilloedema and an occasional VI nerve palsy, and normal level of consciousness. IIH is common in obese females and can lead to visual impairment. Prompt diagnosis and treatment are needed to prevent potentially permanent visual loss. The incidence of IIH in obese women was 11.9 per 1,00,000 per year. Upto $90 \%$ patients were overweight .

\section{Case Report}

A 50 years old female presented with global headache and diplopia on the left side for which she went to an opththalmologist. She was given treatment for 8 days but there was no relief and she came to us with chief complaints of headache and diplopia since 10 days.

On clinical examination, the patient was obese with weight of $121 \mathrm{~kg}$ and height of $165 \mathrm{~cm}$ ( BMI of 44 ). Patient was conscious,oriented, had a pulse rate of $80 / \mathrm{min}$ and blood pressure of $130 / 80 \mathrm{mmHg}$. She had horizontal diplopia on left gaze .Central nervous system examination was normal. Patient was diagnosed case of Diabetes Mellitus type II, Hypertension and Ischemic Heart disease since last 10 years and on regular treatment with anti-diabetic, anti-hypertensive and aspirin therapy. She had no history of consumption of oral pills or any other medicine in the past. On admission, the blood pressure and blood sugar values were normal. Investigation revealed Hba1c of 6.7. Thyroid functions were normal. Ultrasound of abdomen showed fatty liver. Fundus examination showed bilateral disc edema ( papilloedema ). Perimetry showed borderline normal study. MRI brain was not suggestive of ventricular dilatation and there was hypoplastic sigmoid sinus on the left side. MR angiography and MR venography were also normal.

Clinical suspicion of Idiopathic intracranial hypertension was confirmed. She was put on Diamox and short steroid therapy, she improved.

Patient made a good recovery after Diamox and steroid therapy at one month.

On discharge she was advised a 35 mins walk per day 5 times a week. Anti-obesity measures in the form of voglibose, exercise and diet control were prescribed which reduced her weight in 2 months from $121 \mathrm{~kg}$ to $113 \mathrm{~kg}$.

Patient has been under follow up and after 1 month of treatment, she did not have any complaints of 
diplopia and headache.This case has been presented with a view to highlight the entity of Idiopathic intracranial hypertension in a case obese female.

\section{Discussion}

We have discussed a case of idiopathic intracranial hypertension with obesity. IIH is a syndrome characterized by elevated intracranial pressure that usually occurs in obese women of childbearing age ${ }^{1}$. Foley coined the term Idiopathic intracranial hypertension in 1955 but reports from the 1980's demonstrated the high incidence of visual loss ${ }^{2,3}$. The annual incidence of BIH is $0.9 / 100000$ person and 3.5/100000 in females 15-44 years of age. It is increasing in incidence in parellel with the current epidemic of obesity ${ }^{4,5}$. Generally causes of IIH are endocrine ${ }^{6}$ like adrenal insuffiency, cushings syndrome, hypoparathyroidism, hypothyroidism and hyperthyroidism, drugs like doxycycline,levothyroxine,lithium,nitrofurantoin,tamoxifen,tetracycline,pancreatin and chronic renal failure and $\mathrm{SLE}^{7}$. A case control study has found a strong association between IIH and obesity and with weight gain during the 12 months before the IIH diagnosis. In this study there was no evidence the IIH was associated with any other medical condition or pregnancy ${ }^{8}$. There was no drug history in the past to suggest causation of IIH.

The symptoms of Idiopathic intracranial hypertension patients are headache (94\%), transient visual obscurtions (68\%), pulse synchronous tinnitus (58\%), photopsis (54\%), and retrobulbar pain (44\%). visual loss and diplopia are less common with Idiopathic intracranial hypertension. Headache,nausea,vomiting and visual disturbances are the most common presenting features ${ }^{9}$. The headache profile of the IIH patient is that of severe daily pulsatile headache which is generally throbbing, worst in the morning hours and aggravated on straining, coughing, or changing of posture ${ }^{10}$.

Visual obscurations are episodes of transient blurred vision of 30 seconds and are followed by visual recovery to baseline. Visual obscutions occus in about 2/3rd of Idiopathic intracranial hypertension patients ${ }^{11}$. Pulsatile intracranial noises or pulse synchronous tinnitus is common in Idiopathic intracranial hypertension . Papilloedema ,optic disc edema due to increased intracranial pressure is the cardinal sign of Idiopathic intracranial hypertension. Optic disc edema either directly or indirectly is the cause of visual loss of Idiopathic intracranial hypertension. The higher the grade of papilloedema,the worse is the visual loss ${ }^{12}$.

Horizontal diplopia is reported in about $1 / 3 \mathrm{red}$ of Idiopathic intracranial hypertension patients and 6th nerve palsy are found in $10-20 \%{ }^{13}$.

On perimetry, visual field loss occurs in almost all cases of Idiopathic intracranial hypertension in later stages. Visual loss in almost one eye was found in $96 \%$ of patients with goldmans perimetry using a disease specific stategy and in $92 \%$ with automated perimetry ${ }^{14}$.

There is currently no consessus on the management of $\mathrm{IIH}^{15}$. Management is initially medical with weight reduction if obese and diuretic therapy. CSF divergence therapy may be required for visual disturbances ${ }^{16}$.

The aim of treatment is relief of all the symptoms of raised ICT and prevention of progression of optic nerve damage ${ }^{17}$. Since marked weight gain is a predictor of of visual disorientation and papilloedema can resolve with modest weight loss, institution of low salt diet and regular exersice appears to be beneficial for Idiopathic intracranial hypertension patients.

Acetazolamide a carbonic anhydrase inhibitor is the drug of 1st choice. It has been shown to reduce papilloedema and decrease the CSF pressure ${ }^{18,19}$. Mac Carty and Reed ${ }^{20}$ showed that acetazolamide reduces the CSF flow. Steroids are still used to treat Idiopathic intracranial hypertension but their mechanism of action remains unclear. Surgical interventions may be used if the others methods are ineffective. Surgical openions include $^{21}$ :

* CSF diversion ( lumbo-peritoneal or ventriculo-peritoneal shunt)

* Intracranial venus sinus stenting

* Optic nerve sheath fenestrations (decompression)

Optic nerve sheath fenestration is now the currently favoured traetment of Idiopatbhic intracranial hypertension in adults with deteriorating visual functions despite medical managemnt. The procedure succesfully relieves papilloedema, rapidly recovering visual loss in most cases ${ }^{22,23}$.

A study of EJ Rowe ${ }^{24}$ and NJ Sarkies ${ }^{25}$, to evaluate the association between obesity and IIH whether there is relationship between the visual outcome ,70.5\% patients were found. A high degree of obesity was associated with poor visual outcome and identified as a risk factor for poor outcome. A prospective study by Wall and George $^{26}$ showed recent weight gain was significantly associated with worsening vision. Ireland et all ${ }^{27}$ have reported a singnifiant weight gain in IIH pateints during the 6 months proceding diagnosis and their study confirmed a strong association between IIH and obesity and weight gain during the 12 months before the diagnosis. 


\section{Conclusion}

Idiopathic intracranial hypertension is characterized by elevated CSF pressure of unknown case. It is predominantly a disease of women in the childbearing age. Although the cause of IIH remains obscure, it has become clear that the loss of visual functions is common and the patients may progress to blindness if untreated. Most of the cases respond to acetazolamide and short course of steroids coupled with weight reduction by exersice and diet control.

\section{Reference}

[1]. Biousse V; Idiopathic intracranial hypertension:Diagnosis, monitoring and treatment.RevNeurol (Paris). 2012 Oct;168(10):673-83. doi: 0.1016/j.neurol.2012.07.018. Epub 2012 Sep 14.

[2]. Corbett JJ, Savino PJ, Thompson HS, et al. Visual loss in pseudotumor cerebri. Follow-up of 57 patients from five to 41 years and a profile of 14 patients with permanent severe visual loss. Arch Neurol. 1982;39:461-474.

[3]. Wall M, Hart WM, Jr., Burde RM. Visual field defects in idiopathic intracranial hypertension (pseudotumor cerebri) Am J Ophthalmol. 1983;96:654-669. [

[4]. Durcan FJ, Corbett JJ, Wall M. The incidence of pseudotumor cerebri. Population studies in Iowa and Louisiana. Arch Neurol. 1988;45:875-877.

[5]. Radhakrishnan K, Ahlskog JE, Cross SA, Kurland LT, O'Fallon WM. Idiopathic intracranial hypertension (pseudotumor cerebri). Descriptive epidemiology in Rochester, Minn, 1976 to 1990.Arch Neurol. 1993;50:78-80.

[6]. Raoff N, Sharrack B, Pepper IM, et al; The incidence and prevalence of idiopathic intracranial hypertension in sheffield, UK. Eur J Neurol. 2011 oct; 18910):1266-8.

[7]. Digre KB;Not so benign intracranial hypertension. BMJ. 2003 Mar 22;326(7390):613-4.

[8]. Wall M, George D. Idiopathic intracranial hypertension. A prospective study of 50 patients. Brain.1991;114:155-180.

[9]. Amacher AL, Spence JD. Spectrum of benign intracranial hypertension in children and adolescents. Child's Nerv Syst 1985;1:81-6.

[10]. Wall M. The headache profile of idiopathic intracranial hypertension. Cephalalgia. 1990;10:331-335

[11]. Wall M. The morphology of visual field damage in idiopathic intracranial hypertension: an anatomic region analysis. In: Mills RP, Heijl A, editors. Perimetry Update 1990/1991. Kugler Publications; Amsterdam: 1991. pp. 20-27.

[12]. all M, White WN. Asymmetric papilledema in idiopathic intracranial hypertension: prospective interocular comparison of sensory visual function. Invest Ophthalmol Vis Sci. 1998;39:134-142.

[13]. Wall M. The morphology of visual field damage in idiopathic intracranial hypertension: an anatomic region analysis. In: Mills RP, Heijl A, editors. Perimetry Update 1990/1991. Kugler Publications; Amsterdam: 1991. pp. 20-27.

[14]. Fraser C, PlantGT; The syndrome of pseudotumour cerebri and idiopathic intracranial hypertension.CurrOpin Neurol.2011 Feb;24(1):12-7. doi: 10.1097/WCO.0b013e328341f94a.

[15]. Acheson JF; Idiopathic intracranial hypertension and visual function. Br Med Bull. 2006;79-8

[16]. Digre KB;Not so benign intracranial hypertension. BMJ. 2003 Mar 22;326(7390):613-4.

[17]. Johnson LN, Krohel GB, Madsen RW, March GA., Jr. The role of weight loss and acetazolamide in the treatment of idiopathic intracranial hypertension (pseudotumor cerebri) Ophthalmology.1998;105:2313-2317.

[18]. Welch K. The intracranial pressure in infants. J Neurosurgery 1980;52:693-9

[19]. Corbett JJ. Problems in the diagnosis and treatment of pseudotumour cerebri. Am J Neurol Sci 1983;10:221-9.

[20]. McCarthy KD, Reed DJ. The effect of acetazolamide and furosemide on CSF production and choroid plexus carbonic anhydrase activity. J Pharmacol Exp Ther. 1974;189:194-201.

[21]. Tomsak RL, NiVenegger AS, Remler BF. Treatment of pseudotumour cerebri with Diamox (acetazolamide). JClin Neuroophthalmol $1988 ; 8: 93-8$

[22]. 3 Corbett JJ, Nerad JA, Tse DT, et al. Results of optic sheath fenestration for pseudotumour cerebri: the lateral orbitotomy approach. Arch Ophthalmol 1988;106:1391-7.

[23]. Sergott RC, Savino PJ, Bosley TM. Modified optic nerve sheath decompression provides long term visual improvement for pseudotumour cerebri. Arch Ophthamol 1988;106: 1384-90.

[24]. Corbett JJ, Savino PJ, Thompson S, Kansu T, Schatz NJ, Orr LS, Hopson D. Visual loss in pseudotumor cerebri. Arch Neurol 1982; 39: $461 \pm 474$.

[25]. Digre KB, Corbett JJ. Pseudotumor cerebri in men. Arch Neurol 1988; 45: $866 \pm 872$.

[26]. Ireland B, Corbett JJ, Wallace RB. The search for causes of pseudotumor cerebri; a preliminary case controlled study. Arch Neurol 1990; $47: 315 \pm 320$

[27]. Wall M, George AE Idiopathic intracranial hypertension. A prospective study of 50 patients. Brain 1991; 114: $155 \pm 180$. 